\title{
Informed Cannabis Policies on Canadian Campuses: Toward the Protection of Youth and Young Adults
}

\author{
Tristan Rebecca Kaitlyn Sinnatamby ${ }^{1}$, Joel Agarwal ${ }^{2}$, Emad Saad ${ }^{3}$ \\ ${ }^{1}$ Department of Physiology, University of Alberta, Edmonton, Alberta \\ ${ }^{2}$ Department of Biological Sciences, University of Alberta, Edmonton, Alberta \\ ${ }^{3}$ Department of Medicine, University of Alberta, Edmonton, Alberta \\ Corresponding author: sinnatam@ualberta.ca
}

\section{ABSTRACT}

Introduction: The legalization of cannabis across Canada in October 2018 introduced issues including regulation at different levels, public and individual education, and discussions about cannabis product safety. We aimed to discuss ineffective and effective cannabis use policy on campuses and associated public areas, given the known short-term and long-term effects pertaining to its neurologic, pulmonary, and purported medicinal effects. Cannabis interferes with many of the body's basic and executive (higher-level) functions. It is also associated with long-term harmful effects when chronically used. The purpose of this paper is to review and further discuss the responsibility local governments and educational institutions have for creating policies and regulations around cannabis use, particularly within post-secondary institutions, and for implementing educational strategies to promote public knowledge of cannabis.

Methods: Peer-reviewed articles published in the last 10 years were searched for through the MEDLINE database. In addition, national and local health-related websites discussing cannabis policies were reviewed and collated. Expert opinions were also sought out to provide further information and resources.

Results: 31 peer-reviewed articles and 12 professional websites were retrieved and reviewed. Correspondences with individual experts aware of and involved with campus cannabis policies also provided relevant resources and data used in this document.

Conclusion: Smoke-free campus policies create the best health outcomes for the campus population. As well, creating effective and properly regulated policies and prioritizing public education is pertinent especially on universities where the population demographic is relatively young.

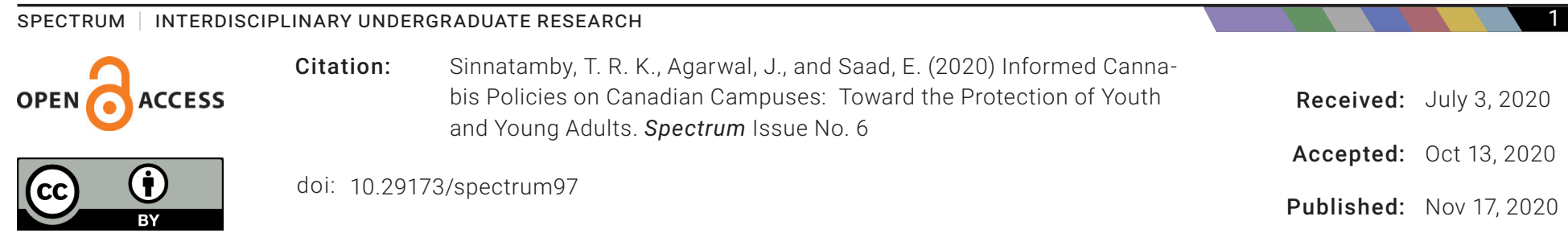




\section{Introduction}

The October 2018 legalization of cannabis in Canada has brought about a major increase in social acceptance of its use, particularly amongst Canadian youth and young adults. ${ }^{1}$ Although major decisions are made at the federal level, each province, territory, and municipality is responsible for creating subsequent policies within their jurisdiction in the post-legalization context. ${ }^{1}$ Educational institutions in Canada, including post-secondary institutions, need special attention given the higher use of cannabis among the age demographics (18-24 years old) primarily represented in these settings. Additionally, this relatively young group has the potential for greater long-term harm related to cannabis use. Cannabis can be consumed in various forms including "dry weed", bongs, edibles, and vaporizers - all of which use various chemicals found in the cannabis plant. ${ }^{2,3}$ The use of this drug, particularly when inhaled, has many acute and long-term detrimental effects. Action of local governments and educational institutions is needed, with the aim of educating the public and creating policies to protect and promote the health of all individuals. Through assessing effectiveness of policies and educational initiatives, this paper will discuss possible solutions to creating effective policies pertaining especially to regulation of recreational cannabis use on university campuses.

There appears to be an increase of cannabis use in Canada, with the past 16 years showing a slowly increasing trend. ${ }^{4-8}$ The rate of cannabis use recorded by annual Statistics Canada surveys from 2004-2017 showed a 60\% increase in Canadian use overall. ${ }^{4}$ This increasing trend seems to still be present with recent Statistics Canada data from 2018 and 2019 showing a slight increase in national and Albertan percent of cannabis use post-legalization. ${ }^{9}$ Changes like this usually do not reach their full effect for a few years, suggesting the full outcome of this legalization remains currently unknown. ${ }^{10,11}$ One study supported this idea by finding a significant increase in cannabis use only occurred a few years after implementation of more permissive retail restrictions. ${ }^{11}$ This was due to the time needed for cannabis retailers to set up and create easier access to the drug. ${ }^{11}$

Cannabis is used for multiple medicinal purposes; however, it also has many detrimental effects that should not be ignored. ${ }^{12-14}$ With its legalization, it is paramount that potential users are provided accurate information regarding both its beneficial and harmful effects. These educational measures must be prioritized by government and other policy makers in Canada and also by educational institutions. Currently, limited studies are available on the human health effects of cannabis, especially pertaining to causation - with existing research being largely observational and controversial. ${ }^{12,15,16}$ As well, a risk of bias and variability in populations and other parameters also may influence the variable results. Prospective clinical trials are needed to establish causation relationships between cannabis and human health, as opposed to retrospective studies that can only determine associations. Legalization and increased accessibility of cannabis will hopefully result in increased research on this topic, especially with increases in research funding and tax revenue. As well, being the first G7 country to legalize cannabis, better research can be conducted on national cannabis legalization to help direct policymaking. ${ }^{1}$ Although certain American states have legalized recreational cannabis, the lack of a uniform national policy, the relatively early stages of legalization, and the inconclusiveness of the overall effects on population cannabis use makes it harder to use this data to predict possible long-term effects of Canadian legalization. ${ }^{17}$ Presently, legalization may mislead individuals, including young adults, toward safer perceptions of cannabis use and consequences, thereby resulting in a more carefree attitude towards it. 


\section{Methods}

A comprehensive MEDLINE search was conducted for peer-reviewed articles focusing on the terms 'cannabis', 'cannabis AND policy', 'cannabis AND legalization', and 'drugs AND education' over the past decade (January 1, 2010 - April 31, 2020). Search results were further limited to humans and core clinical journals. Reference lists from retrieved literature were also reviewed to find other potential resources. Published literature pertaining to cannabis' medical use, acute effects, and longterm effects were selected as well as literature discussing policymaking and educational strategies and problems. Current literature, especially pertaining to prevalence rates and cannabis effects, were prioritized in order to get the most up to date information. Peer-reviewed papers discussing North American policies (Canada and the United States) were prioritized. Papers repeating information already provided by multiple other papers were excluded unless they provided additional information. Articles retrieved that did not relate to or were off topic were also excluded. This was done in conjunction with a review of online government, non-profit health organizations, and post-secondary university websites discussing cannabis poli- cies, health policies, or campus health promotion. Correspondence and meetings were conducted with local experts on policies, cannabis or other substances, and public health. (Figure 1)

\section{Results}

A total of 31 articles and 12 authoritative health-related websites were retrieved and reviewed (Table 1). Discussions with professionals led to obtaining further relevant websites and resources including the 4 National College Health Assessment (NCHA) surveys $(2011,2013,2016,2019)$. Information was combined and summarized below.

Reviewed articles showed the alleged medicinal benefits of cannabis span the treatment of chronic neuropathic pain, vomiting, nausea, and management of cancer therapy side effects. ${ }^{15}$ These treatments utilize the various effects cannabis has on an individual's brain through chemicals that directly target the nervous system. The primary and most potent psychoactive component (chemical) in cannabis is tetrahydrocannabinol (THC), which may be modified or removed from medicinal cannabis products to eliminate some of its unwanted psychoactive effects. ${ }^{14,16,18}$ THC, mainly used recreationally, activates cannabinoid receptors in the nervous sys-

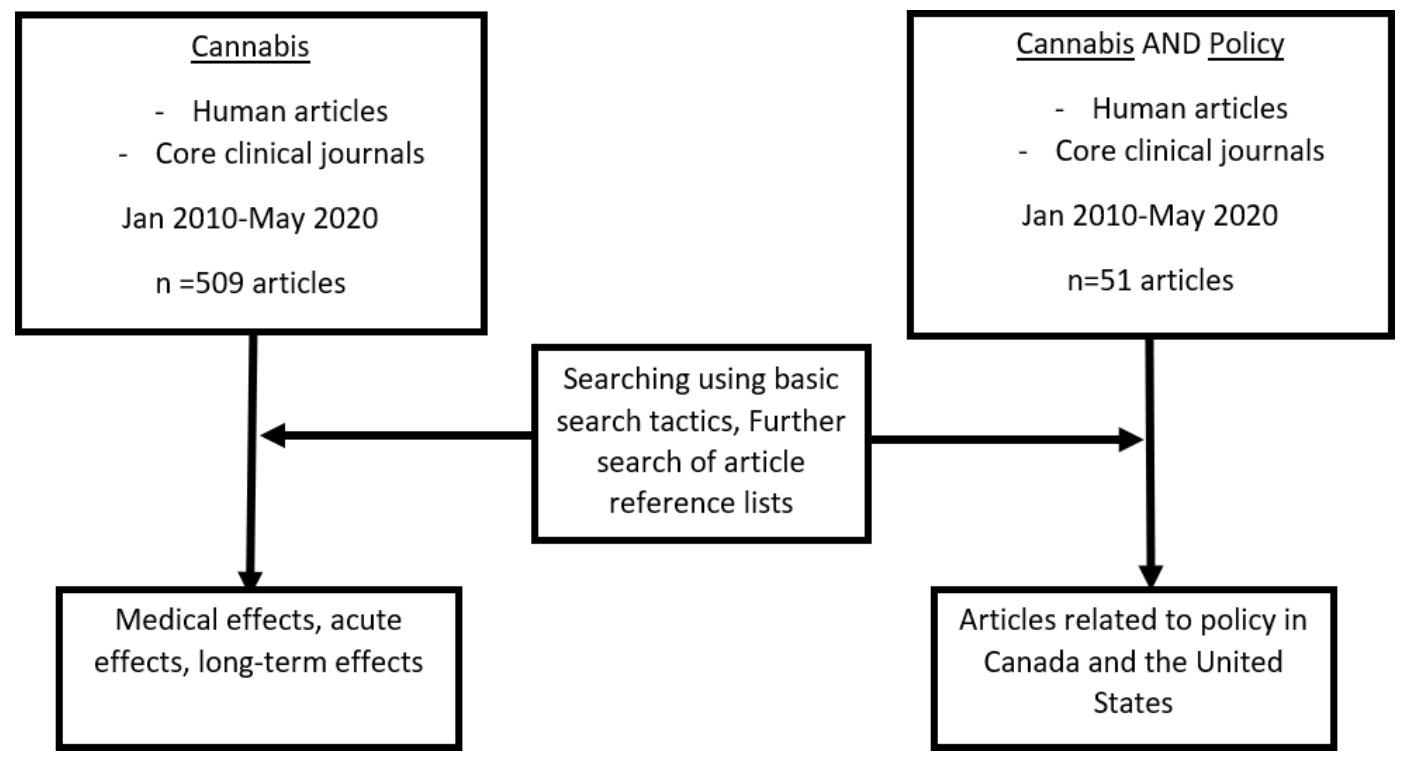

Figure 1. Search strategy for locating literature related to cannabis through MEDLINE database. Two examples of search terms were used to illustrate this strategy. 
Table 1. Summary of Peer-Reviewed Published Literature About Cannabis Effects and Policy.

\begin{tabular}{|c|c|}
\hline Author (Publication Year) & Pertinent Points \\
\hline Struble CA, et al. (2019) & $\begin{array}{ll} & \text { Increased potency of THC over the years } \\
\text { - } & \text { Lower discontinuation rates with earlier use } \\
\text { - } & \text { Lower perceived risk in youth } \\
\text { - } & \text { Increased effects when smoking cannabis }\end{array}$ \\
\hline Johnson JK, et al. (2019) & $\begin{array}{l}\text { - } \quad \text { Permissive changes in cannabis regulations and possible negative effects } \\
\text { - } \quad \text { Increased harm for adolescents and young adults } \\
\text { Study example of the delayed effects of permissive changes on cannabis use seen in } \\
\text { Washington State }\end{array}$ \\
\hline Tashkin DP, et al. (2019) & $\begin{array}{l}\text { - } \quad \text { Smoking cannabis as a joint (combustion reaction occurs) } \\
\text { - } \quad \text { Acute and chronic affects of cannabis smoke inhalation on the airways } \\
\text { - } \quad \text { Gaps in knowledge and controversial results } \\
\text { - } \quad \text { Cannabis most commonly consumed through inhalation }\end{array}$ \\
\hline Caulley L, et al. (2018) & $\begin{array}{l}\text { - A case study of a } 31 \text {-year old woman with chronic pain } \\
\text { - } \quad \text { Debating both the benefits of using medical marijuana and the detriments }\end{array}$ \\
\hline Mashoon Y, et al. (2019) & $\begin{array}{ll}\text { - } & \text { Chemical components in cannabis } \\
\text { - } & \text { Seemingly decreased perception of cannabis risks } \\
\text { - } & \text { Brain maturation during adolescence and young adulthood } \\
\text { - } & \text { Effects of cannabis use at an early age on neurological outcomes }\end{array}$ \\
\hline Hauser W, et al. (2017) & $\begin{array}{l}\text { - } \quad \text { An overview of medicinal cannabis and its uses for various therapies based on research } \\
\text { - } \quad \text { Reviewing the efficacy of the various treatments }\end{array}$ \\
\hline Volkow ND, et al. (2014) & $\begin{array}{l}\text { - Reviewing the adverse effects of cannabis both on the body and on a person's life and } \\
\text { achievements } \\
\text { Discussing gaps in knowledge and limitations of current research }\end{array}$ \\
\hline Hamilton AD, et al. (2019) & $\begin{array}{ll}\text { - } & \text { Reviewing the effects of cannabis legalization in the US } \\
\text { - } & \text { Discussing the limitations of our knowledge on legalization effects currently }\end{array}$ \\
\hline Cohen K, et al. (2019) & $\begin{array}{ll}\text { - } & \text { Cannabis chemical components } \\
\text { - } & \text { Controversial effects of governmental cannabis regulation changes (US) } \\
\text { - } & \text { Research on medicinal uses } \\
\text { - } & \text { Neurological and pulmonary acute and chronic cannabis effects, tolerance and addiction } \\
\text { - } & \text { Effects of early cannabis use } \\
\text { - } & \text { Cannabis is most commonly consumed through inhalation }\end{array}$ \\
\hline Murray JB. (1986) & $\begin{array}{ll}\text { - } & \text { Discussion of cannabis, its components, effects, administration } \\
\text { - } & \text { Effects of cognitive, psychomotor, and psychological performances }\end{array}$ \\
\hline Gobbi G, et al. (2019) & $\begin{array}{l}\text { - } \quad \text { Supposed increase in cannabis use } \\
\text { - } \quad \text { Cannabis chemical components } \\
\text { Early cannabis use associations with increased risks of depression and anxiety as young } \\
\text { - } \quad \text { Neurological and pulmonary effects of cannabis }\end{array}$ \\
\hline Layden JE, et al. (2020) & $\begin{array}{ll}\text { - } & \text { Recent occurrence of vaping related lung injury and death in the United States } \\
\text { - } & \text { Chemicals, products, and devices possibly linked to this }\end{array}$ \\
\hline Biehl JR, et al. (2015) & $\begin{array}{l}\text { - } \quad \text { Cannabis smoking has faster effects and better bioavailability } \\
\text { - The affects of cannabis smoking on the airways } \\
\text { - Use of tobacco and cannabis }\end{array}$ \\
\hline Graves BM, et al. (2020) & $\begin{array}{ll}\text { - } & \text { Analysis of cannabis 'joint' smoke and cigarette smoke } \\
\text { - } & \text { Comparing amounts of characterized chemicals in each }\end{array}$ \\
\hline Kelsall D. (2017) & $\begin{array}{ll}\text { - } & \text { Discussing future legalization of cannabis in Canada } \\
\text { - } & \text { Discussing the lack of protection for younger individuals } \\
\text { - } & \text { Outlining why cannabis should not be used in younger individuals }\end{array}$ \\
\hline $\begin{array}{l}\text { Hammond CJ, et al. } \\
(2020)\end{array}$ & Reviewing the effects of cannabis legalization in the US on youth use patterns and trends \\
\hline Mader J, et al. (2019) & $\begin{array}{l}\text { - } \quad \text { Analyzing factors affecting lifetime and/or high-risk cannabis use } \\
\text { - Using a Canadian university population }\end{array}$ \\
\hline $\begin{array}{l}\text { Zuckermann AME, et al. } \\
\text { (2019) }\end{array}$ & $\begin{array}{l}\text { - Conducted a prospective cohort study using self-administered questionnaires } \\
\text { - Looked at Canadian students, found access to and overall use of cannabis slowly } \\
\text { increasing }\end{array}$ \\
\hline
\end{tabular}


Table 1. Summary of Peer-Reviewed Published Literature About Cannabis Effects and Policy. (Continued).

\begin{tabular}{|c|c|}
\hline Yeung MEM, et al. (2020) & $\begin{array}{l}\text { - Studying the outcomes of recreational cannabis legalization through looking at changes in } \\
\text { cannabis-related public health outcomes in Alberta }\end{array}$ \\
\hline Vogel L. (2018) & $\begin{array}{l}\text { - Discussion of Colorado cannabis legalization and its effects } \\
\text { There have been harmful effects but also some outcomes that were less impacted than } \\
\text { what was predicted }\end{array}$ \\
\hline Russell C, et al. (2018) & $\begin{array}{l}\text { - } \quad \text { Prevalence, outcomes, and current available routes of administration for cannabis } \\
\text { - } \quad \text { Comparing effects related to routes of administration }\end{array}$ \\
\hline Fallin A, et al. (2015) & $\begin{array}{l}\text { - Study looking at } 8 \text { four-year college and university campuses in California } \\
\text { Tobacco- and smoke-free policies decrease smoking on campus and secondhand smoke } \\
\text { better than more permissive policies }\end{array}$ \\
\hline Lee JG, et al. (2013) & $\begin{array}{l}\text { - Study looking at two-year American community college campuses } \\
\text { Evidence of less smoking on campuses with tobacco- and smoke-free policies compared } \\
\text { to more permissive policies }\end{array}$ \\
\hline Tan WC, et al. (2018) & $\begin{array}{ll}\text { - } & \text { Discussing public views of cannabis } \\
\text { - } & \text { Reviewing possible harms of smoking cannabis and its links to tobacco }\end{array}$ \\
\hline Stanbrook MB. (2016) & $\begin{array}{ll}\text { - } & \text { E-cigarettes and youth - social perceptions } \\
\text { - } & \text { Associations between using both e-cigarettes and tobacco } \\
& \text { Discussing why its use is so prevalent in younger individuals }\end{array}$ \\
\hline Brown S. (2019) & $\begin{array}{l}\text { Discussing the anticipated health outcomes of cannabis legalization } \\
\text { The expected increase in emergency visits related to cannabis especially due to legaliza- } \\
\text { tion of edibles }\end{array}$ \\
\hline Caputi TL. (2020) & $\begin{array}{l}\text { - Big marijuana company's and biased, deceptive marketing using poor research } \\
\text { - Using small-scale studies and biased research to mislead consumers on blogs and social } \\
\text { media }\end{array}$ \\
\hline Watson TM, et al. (2019) & $\begin{array}{ll}\text { - } & \text { Canadian provincial, territorial, and municipal governments and responsibilities post-legal- } \\
\text { ization } & \\
\text { - } & \text { Priority of the government for public education } \\
\text { - } & \text { Examples of ineffective educational strategies } \\
\end{array}$ \\
\hline Lazard AJ, et al. (2018) & $\begin{array}{l}\text { - Reviewing what a population of American youth and young adults prefer in online educa- } \\
\text { tional initiatives }\end{array}$ \\
\hline $\begin{array}{l}\text { Richardson AK, et al. } \\
(2010)\end{array}$ & $\begin{array}{ll}\text { - } & \text { Discussing the success of the Truth Initiative in the US } \\
\text { - } & \text { Reviewing the successful strategies used }\end{array}$ \\
\hline Caulkins JP, et al. (2020) & $\begin{array}{l}\text { - } \quad \text { Need for guidelines for lower-risk cannabis use as preventing all use is not reasonable } \\
\text { - } \quad \text { Possible normalization of cannabis use } \\
\text { - Guidelines must also prevent industry influenced cannabis research }\end{array}$ \\
\hline
\end{tabular}

tem, resulting in neurological cognitive and motor effects, and the "high" associated with cannabis use. ${ }^{16,18}$ The primary nonintoxicating chemical in cannabis is cannabidiol (CBD), used more for cannabis' medical uses such as reducing anxiety than for recreational purposes. ${ }^{14,16,18}$ Cannabis' components, including THC and mainly CBD, are utilized in therapeutic treatments such as increased neural reward signaling for depression and analgesic effects for chronic pain. ${ }^{16,18}$ Its analgesic effects are the most established, however still require further research examining efficacy, mechanisms, and risks. ${ }^{13,15,18}$ Additionally, studies have found mild adverse effects on cognitive and physical function among patients using medicinal cannabis. ${ }^{13,18}$ This indicates a current need for caution when using medicinal cannabis. Although cannabis has helped individuals, well-designed conclusive research, such as experiments and clinical trials, is needed to elucidate the efficacy, harms, and therapeutic potential of medicinal cannabis use. ${ }^{18}$ The topic of medicinal cannabis is controversial, further emphasizing why effective policies and better education on cannabis risks are needed - especially for the younger population.

Cannabis affects many neurological, cognitive, and systemic functions in the body; most of its known effects are related to THC. The acute effects of cannabis include disruption of sensory perception, 
learning, movement, coordination, memory, attention, and executive functions (i.e. inhibition and emotional regulation). Furthermore, cannabis use may lead to euphoria, relaxation, hallucinations, cannabis-induced hyperemesis (repeated and severe vomiting episodes), anxiety, panic reactions, and psychosis. ${ }^{18,19}$ While there is a wide range of potential side effects, the more common acute effects include anxiety, various cognitive changes, tachycardia (fast heart rate), and certain less severe or long-term psychotic symptoms. ${ }^{18}$ Cannabis affects many neural connections in the brain including decreasing stress reactivity and glutamate (excitatory) signaling and increasing endogenous opioid release. ${ }^{14,18}$ Endogenous opioids are produced by the brain to act as natural pain-relieving chemicals. Altering the normal levels of excitatory glutamate and opioid production can affect the homeostasis of the body. Long-term use may result in serious chronic effects, such as mood, anxiety, and other mental health problems, loss of intelligence quotient (IQ), and increased risks of respiratory, reproductive, and cardiovascular issues. ${ }^{14,18,19}$ As well, chronic cannabis use is associated with brain structure and function abnormalities, especially in the limbic and prefrontal areas that are greatly affected by THC. ${ }^{18,20}$ These two structures are important in controlling emotion, memory, and executive functions which make them integral to everyday life. "Cannabis withdrawal syndrome" is a problem due to cannabis stimulating dopamine release in the reward signalling system of the brain. ${ }^{14,16}$ Therefore, the stimulation of reward signalling can result in greater addiction to the substance due to the benefits felt when taking it. Cannabis can also be a possible risk factor for altering a person's sensitivity to other related drugs. ${ }^{16}$ In rare cases, cannabis can result in death due to mixing with other substances. This can be seen in the recent crisis regarding deaths linked to vaping with THC or other compounds in the United States. ${ }^{21}$ Therefore, the various risks of cannabis use must be carefully evaluated against the possible benefits - especially with early onset of use.
Inhalation of cannabis comes with additional harmful effects especially pertaining to the respiratory system. As inhalation of cannabis is the most common method for consumption, providing knowledge about its increased risks is important. ${ }^{12,18,19}$ Inhaled cannabis can increase oxidative stress resulting in cell and tissue damage, apoptosis of cells (controlled cell death), and risk of pulmonary disorders. ${ }^{2,22}$ Chronic cannabis inhalation has been associated with immunosuppression in the lungs and increased risks of lung cancer, however results for the latter are inconclusive. ${ }^{12,18,22}$ Common symptoms include shortness of breath, chronic bronchitis symptoms including coughing and sputum, and airway irritation and inflammation. ${ }^{12}$ Inhalation of cannabis results in a significantly higher blood THC concentration due to greater bioavailability (a higher concentration enters the blood), and a quicker and greater onset of effects when compared to oral intake. ${ }^{3,19,22}$ Legalization has created access to more standardized and regulated cannabis products, however a recent Canadian study found there were still many harmful chemicals such as nitric oxides, phenols, and hydrogen cyanide present in cannabis "joint" smoke resulting from multiple combustion reactions. ${ }^{23}$ These chemicals can be carcinogenic, teratogenic and may affect fetal development, or mutagenic and may cause mutations resulting in regulated cannabis products still having potentially harmful outcomes. ${ }^{23}$ Some of these chemicals are also in cigarettes while some are only in cannabis smoke. ${ }^{12,22,23}$ Therefore, inhaling cannabis, especially chronically, creates risks both from direct cannabis effects and resultant respiratory effects.

Younger Use Outcomes:

Cannabis particularly affects younger individuals physiologically and psychologically as their bodies are still growing and developing. The brain is not fully developed until around the age of $25 .^{24}$ Important factors such as neuronal myelination and experience-based synaptic pruning, removing unused neuron connections to increase efficiency and learning, occur at higher rates in adolescents and young adults, making this an important time for 
brain development. ${ }^{14}$ Cannabis dependence seems to increase by around $8 \%$ when an individual is introduced to the substance at an early age. ${ }^{24}$ This increase has been found in other studies. ${ }^{14}$ Many studies also show greater cannabis-related brain structure and function abnormalities, especially in cortical areas, and neural signalling pathway abnormalities in those with early onset of cannabis use. ${ }^{14,24}$ Premature use may create problems with learning and cognitive performance possibly due to the brain structure and signalling abnormalities; results on performance impairment are controversial and require further research. ${ }^{24}$ Associations have been consistently found between adolescent cannabis use and risks of mood and anxiety disorders that persist into young adulthood. ${ }^{20,24,25} \mathrm{Re}-$ search also indicated early cannabis use increased risk of psychosis even when controlling for genetic and environmental risk factors. ${ }^{25}$ Factors including early onset of cannabis use, living alone, lower religiosity, greater alcohol use, and family history of mental illness (genetics) can contribute to a lower rate of discontinuation resulting in prolonged cannabis use over a lifetime. ${ }^{3,26}$ Using cannabis as a coping strategy, especially with early initiation, and higher frequency of use are all associated with risks of greater cannabis use severity. ${ }^{26}$

Unfortunately, data recorded through Statistics Canada and Health Canada from 2004-2019 consistently show young adult populations (ages 1824) with the highest prevalence of cannabis use in Canada. ${ }^{4,10,27}$ As well, the adolescent population (ages 15-17) had the second highest prevalence of cannabis use in Canada for most surveys in this time period. 4,10,27 Overall, statistics taken in Canada have also indicated Canadian youth seem to have higher cannabis use compared to youth globally. ${ }^{27,28}$ Statistics have also indicated that over the years there appears to have been a decrease in cannabis' perceived risk amongst youth, which can influence them to increase their recreational use. ${ }^{3,14,26}$ Counterintuitively, the most susceptible individuals toward long-term harm from cannabis are most likely to use it. One study reviewing the effects of cannabis policy changes in America over the past 25 years found that although cannabis use has recently been plateauing and even decreasing in youth (ages $<18$ ), it has been increasing continuously in young adults. ${ }^{17}$ This may be influenced in part by increased willingness to record usage; this increasing trend has been seen since as early as 2002 and other age groups have shown decreasing trends in use indicating it is not solely due to the improving social perceptions. ${ }^{17}$ As well, changes due to recreational cannabis legalization in America show the public health impacts of cannabis use such as emergency department visits have increased indicating an increase in total use or higher risk use. ${ }^{29}$ This increase seems to be starting in Canada as well. ${ }^{29}$ With its legalization, these figures are likely to remain high and potentially increase, especially in the legal age group of 18-24. The increased risks of cannabis consumption along with the young legal age (18 or 19) shows why regulation for Canadian young adults must be a priority. ${ }^{1}$

\section{Discussion}

\section{Policymaking and Health Promotion:}

Policies reflecting health promotion strategies require a collaborative structural approach at both the national, provincial, and regional levels. Through the government's attempt to reduce black market sales and increase product safety, it has made public consumption more socially acceptable and created a laissez-faire attitude around its use. With this new social standard, precautions must be taken to maximize the safety of users and non-users alike. As seen in the state of Colorado, which legalized cannabis in 2012, fatal motor vehicle accidents potentially involving cannabis doubled (from $10 \%$ to $20 \%$ ) over the subsequent three year period. ${ }^{30}$ This indicates the importance of implementing effective and enforced safety precautions post-legalization. ${ }^{30}$ If not done properly, the lack of knowledge or consideration for cannabis' effects may foster an increase in dangerous outcomes - as seen in Colorado. Reports from as late as 2015 indicate that North American rates are around $8 \%$ higher than global rates, therefore prevalence was high even before legaliza- 
tion. ${ }^{31}$ With legalization likely increasing cannabis accessibility and use, normalizing public consumption, decreasing perceived harms, and proper regulations, policies, and educational interventions are required to ensure the safety of all Canadians.

In Alberta, although the number of municipalities with outdoor smoking policies have increased dramatically especially since 2016, currently less than half the municipalities have sufficient regulations completely inhibiting smoking or vaping on public spaces such as playgrounds and parks. ${ }^{32}$ Smoking or vaping cannabis in Alberta is restricted within 5 meters of these places, however a uniform provincial regulation restricting smoking and vaping of any substance would be more effective and easier to enforce. ${ }^{32,33}$ These places are highly populated, especially with children, therefore local governments in Canada need to take more action in regulating and enforcing cannabis restrictions in these public areas. University campuses require more attention as they include a large portion of the younger population, many of whom can legally consume cannabis.

Legalization largely affects Canadian university students especially since cannabis use is consistently highest among 18-24-year old in Canada. 4,10 Results from the 4 NCHA surveys carried out at the University of Alberta suggests an increase in weekly and monthly cannabis use amongst this university population, especially recently. 5,6,7,8 Data was collected in 2011, 2013, 2016, and 2019 showing a steeper increase between 2016 and 2019 of $10.1 \%$ in any cannabis use over the past 30 days (compared to a 0.3\% increase between 2013 and 2016; a $0.9 \%$ increase between 2011 and 2013). ${ }^{5,6,7,8}$ Many Canadian universities have regulated cannabis use on campus through policies indicating designated areas for smoking. ${ }^{34}$ Some other campuses do not have smoking areas or any uniform restrictions implemented regarding cannabis use on campus. ${ }^{34}$ These policies create difficulties in regulations and are not found to be as effective at reducing on-campus cannabis use. ${ }^{35,36}$ Campuses require better regulations and more uniform control of substance use all over campuses to better regulate use. The question is how Canadian universities will create a safe and healthy environment for those who smoke cannabis, those who do not, and those who only smoke or vape other substances (i.e. tobacco). Universities must also find ways to reinforce restrictions on recreational cannabis without infringing upon the rights of individuals who require medicinal cannabis. A possible way is to allow the use of ingested (not inhaled) medicinal cannabis for those that require it. Inhaled cannabis is problematic as it brings issues such as second-hand smoke, which impacts nonusers in the vicinity. ${ }^{37}$ Vaporizers, also used to inhale cannabis, create challenges as they are easily concealed and can mask the characteristic smell of cannabis. ${ }^{38}$ The federal government has left many regulating decisions including cannabis store locations, density of stores, and public cannabis consumption restrictions to provincial, territorial, and municipal governments. ${ }^{1}$ Therefore, the proper creation of uniform regulations and policies by local governments as well as educational institutions is pertinent and multifaceted.

Legalization has resulted in the de-stigmatization of cannabis, however creating new rules and boundaries for cannabis has the potential to re-stigmatize it in some respects. This can occur especially if cannabis users are separated from users of tobacco and other substances in their regulations and restrictions. Therefore, it is important to uniformly address the smoking of all harmful substances on campuses and other public areas, especially since they all have detrimental effects to the users and those around them. An effective and recommended way to regulate cannabis and other harmful substances is to create a smoke-free and vape-free campus. Research has shown both smoke-free and tobacco-free campus policies result in reduced reported secondhand smoke and intention to smoke on campuses, and reduced smoking on campuses when compared to more permissive campus policies such as creating designated areas for smoking. ${ }^{35,36}$. As mentioned before, smoking cannabis is the predom- 
inant way it is consumed with $>90 \%$ of cannabis users intaking it through inhalation in 2014. ${ }^{12,18,19,31}$ As well, consuming cannabis through vaporizing has increased in popularity with $61 \%$ of adult cannabis users reporting using this method of administration in a 2016 study. ${ }^{31}$ Therefore, smoke-free and vapefree policies will reduce the majority of cannabis use on campus. This approach will prevent the creation of separate "classes" of legal drug users and will create uniform restrictions for all substances that are easier to implement and enforce on campuses. Other benefits include allowing cleaner air on campuses, fulfilling a right all individuals have. In this way, the harm to nonusers through secondhand smoke exposure will be eliminated. Secondhand smoke has known detrimental effects on an individual's health, therefore this regulation will reduce these risks. ${ }^{36}$ With this uniform policy, special considerations for students living on campus can be considered around using non-inhaled cannabis when needed while still limiting harm to others. Many youth use tobacco alongside cannabis; concurrent tobacco smoking is 6-12 times higher in adolescent and 2-5 times higher in young adult cannabis users. ${ }^{31}$ Information from Alberta Health also indicates a rapid increase in vaping amongst high school students from $8 \%$ in 2014-2015 to $22 \%$ in 2016-2017 when asked about use in the prior 30 days. ${ }^{39}$ Therefore, banning all inhaled substances will reduce the prevalence of many harmful activities, some of which have been increasing in use, on campus and hopefully off campus as well. These policies will result in greater health promotion for those studying and working within post-secondary institutions in Canada.

The prevalence of Canadian universities with 100\% smoke-free policies, even outdoors, has dramatically increased over the past three years (65 as of 2019), however many universities have not taken this step. ${ }^{40}$ Creating a smoke-free campus will not only benefit the health of the campus population but will have other positive outcomes including decreasing costs of cleaning litter such as cigarette butts. ${ }^{40}$ One potential way to create a smoke-free campus is through adopting the Okanagan Charter which aims to create campuses in Canada and globally that focus on health promotion in everything they do, from policymaking to research. ${ }^{2,41}$ In this way, Canadian universities can align with many others, including McMaster University, Queen's University, and the Northern Alberta Institute of Technology (NAIT), in promoting a healthy campus. ${ }^{2}$ Creating a smoke-free campus aligns with the Okanagan Charter's aim of promoting a healthy campus. Restricting orally or topically ingested recreational cannabis on campus will also contribute to promoting a healthy campus lifestyle and reducing campus cannabis use, however regulation of this is harder and less effective than regulation of inhaled substances. Universities such as McMaster University can be used as a framework for successfully promoting health over tobacco and cannabis use. McMaster University campuses went smoke-free in January 2018 to promote health and wellness which they saw as a responsibility they had to their staff, faculty, and students. ${ }^{41}$ Implementation was conducted by representatives from faculty, staff, students, and others so as to include the voices and opinions of the whole campus population in this beneficial policy. ${ }^{41}$ Many Canadian universities have taken steps in controlling cannabis on campus, however to benefit the majority of individuals there needs to be stronger and more regulated policies that include deliberation involving faculty, staff, and students.

\section{Educational Strategies:}

Not only should smoke-free policies be created to regulate cannabis use, but teaching / reminding young adults about its effects should be a priority in accomplishing a safe and healthy campus for everyone. The legalization of edibles in the fall of 2019 brings about the need for more education as there are differences between smoking cannabis and consuming it in alternate forms. ${ }^{42}$ As well, regulations and policies must now differentiate routes of administration as it relates in particular to the individual and nearby nonusers. As seen in Colorado, legalization of edibles increased cannabis-related harmful outcomes such as accidental intakes and 
excessive intoxication due to harder dosage control and slower onset of effects. ${ }^{30,31,42}$ This is why a greater need exists for regulation and education compared to earlier legalization of cannabis in other forms in order to ensure population safety. ${ }^{30,31,42}$ Although restrictions have been placed on cannabis advertisements to reduce promotion towards youth, similar to tobacco restrictions, public education is still pertinent to reducing use. ${ }^{1,33}$ Educating users about the detrimental effects of cannabis is important especially when legalization has resulted in a more relaxed outlook on this drug. Social media can enhance educational interventions and increase its outreach at different universities as it is an effective way to reach most of the young adult population. This is important, especially since many large cannabis companies attempt to use poorly designed, small-scale observational or correlational studies to mislead consumers into believing benefits of cannabis that have not been proven by well-designed experimental studies. ${ }^{43}$ They utilize social media and other online outlets to present these deceptive results, therefore providing properly researched scientific evidence of the effects and outcomes of cannabis through these same outlets will help promote correctly informed cannabis use. ${ }^{43}$

The Canadian government has committed over $\$ 100$ million to cannabis public education, regulation, and awareness. However, it is largely the responsibility of local governments and educational institutes to create educational policies that are effective, especially pertaining to young adults. ${ }^{44}$ When deciding how to educate the public on cannabis, many initiatives have traditionally used risk-focused messaging and 'scare tactics' ${ }^{44}$ This appears to be ineffective, as most individuals have not experienced the risks publicized by these strategies and young adults do not see this as a proper way to educate themselves. ${ }^{44,45}$ Educational interventions need to provide clear science and evidence-based information on cannabis to individuals and groups in an informative and non-antagonizing way. This includes reporting the detri- mental effects but also the purported benefits of cannabis. Research looking at what appeals to and changes the attitudes and subsequent behaviours of individuals shows that young adults prefer novel facts and debunked myths presented so they can learn for themselves without feeling judgement or blame. ${ }^{45}$ Providing information on the common tactics industry uses to mislead consumers is also well received. ${ }^{45}$ The Truth Initiative in the United States is a successful example of how advertisement campaigns helped prevent around 450, 000 American youth from initiating smoking in the span of two years. ${ }^{46}$ It also helped increase the intention for cessation in young adults and created lasting attitude changes. ${ }^{46}$ This campaign presented short clips illustrating the harms of cannabis and exposing tobacco industry faults. ${ }^{46}$ Many current educational initiatives target junior high and high school students. However, one point of improvement is the need to also focus on young adults as they are at a high risk for initiation and progression of substance use as they enter the legal market. ${ }^{46} \mathrm{~A}$ harmonized approach to delivery of education between campuses and public schools with incoming students is critical. Outlining the outcomes pertaining to the younger population should also be a priority. Informing the public about resources available to help with cessation can provide a full educational outline focusing on health promotion and harm reduction. Organizing student-led educational initiatives will also improve the spread of proper knowledge through peer-to-peer discussions. Finally, providing education on all commonly used harmful substances will reduce re-stigmatization of cannabis while educating individuals on many relevant topics.

Knowing cannabis' harms will not completely stop its consumption which is why it is important to teach strategies for minimizing the risks of cannabis use. This can include information on how increased potency, higher frequency, inhaling cannabis via joints, and using synthetic cannabinoids should be avoided due to their higher risk profile. ${ }^{31,47}$ In this way, cannabis' harmful effects can be controlled and potentially reduced in those that choose to use this sub- 
stance or who are trying to quit. The best way to create policies and regulations for young adults is to create an informative and unbiased discussion about legalized cannabis and inhaled cannabis with students across Canadian campuses. As well, this will allow public engagement and input from young adults in the creation of educational policies centered around them. In this way, the public will be effectively educated about cannabis, resulting in informed and safer use and creation of a healthier environment. With the recent crisis regarding deaths linked to vaping with THC in the United States, as mentioned above, it can be seen that a lack of educational measures for products can be life-threatening. ${ }^{21}$

\section{Conclusions}

Legalization of any drug brings about new challenges including appropriately structuring policy development to ensure the long-term health promotion of a society. With a drug like cannabis and its diverse methods of consumption, it is important that individuals are properly informed about its various effects. Therefore, discussion of this topic, especially with youth and young adults, should be prioritized. Additionally, Canadian governments should integrally incorporate the health of young adults into their deliberations related to cannabis. It is also the responsibility of educational institutions across Canada to prioritize the health of their campus population in the same way. The policies centered on cannabis use in Canada, including use on campuses, require more consideration and changes from where they currently are. As well, listening to Canadians' opinions and ideas on cannabis regulation is critical to creating effective rules and regulations. A priority toward smoke-free campuses and more uniform regulations with the health of all individuals in mind can result in enhanced and effective policies.

\section{Acknowledgments}

Mr. Kevin Friese, Dean of Students Office. Mr. Les Hagen, Executive Director, Action on Smoking and Health. Dr. Anne Hicks, Associate Professor FOMD Dr. Dilini Vethanayagam, Associate Professor, FOMD. 


\section{Works Cited}

1. Justice Canada, Health Canada, Public Safety Canada [Internet]. Edmonton: Government of Canada; c2020. Cannabis laws and regulations; 2018 [updated 2020 Jan 23; cited 2020 May 17]; [about 3 screens]. Available from: https://www.canada.ca/en/health-canada/services/drugs-medication/cannabis/laws-regulations.html

2. Sanford J, Bakht A, Arasaratnam G, Cornish P, McGrath R, Macdonald A, et al. Canadian Health Promoting Campuses [Internet]. [Place unknown]: The Canadian Health promoting Campuses Network; c2019. Okanagan Charter; 2015 [cited 2020 Apr 30]; [about 7 screens]. Available from: https://healthpromotingcampuses.squarespace.com/

3. Struble CA, Ellis JD, Lundahl LH. Beyond the bud: emerging methods of cannabis consumption for youth. Pediatric Clin N Am. 2019 Dec;66(6):1087-1097. Available from: https://pubmed.ncbi. nlm.nih.gov/31679599/?from_single_result=19.+Struble+CA\%2C+Ellis+JD\%2C+Lundahl+LH.+Beyond+the+bud\%3A+emerging+methods+of+cannabis+consumption+for+youth.+Pediatric+Clin+N+Am.+2019+Dec\%3B66\%286\%29\%3A1087-1097.\&expanded_search_query=19.+Struble+CA\%2C+Ellis+JD\%2C+Lundahl+LH.+Beyond+the+bud\%3A+emerging+methods+of+cannabis+consumption+for+youth.+Pediatric+Clin+N+Am.+2019+Dec\%3B66\%286\%29\%3A1087-1097.

4. Rotermann M. Analysis of trends in the prevalence of cannabis use and related metrics in Canada. Statistics Canada [Internet]. 2019 Jun;30(6):3-13. Available from: https://www150.statcan.gc.ca/n1/ en/pub/82-003-x/2019006/article/00001-eng.pdf?st=04zrOyJg

5. American College Health Association. American College Health Association-National College Health Assessment II: University of Alberta Executive Summary Spring 2011. Linthicum, MD: American College Health Association; 2011. [cited May 10, 2020]. 18 p.

6. American College Health Association. American College Health Association-National College Health Assessment II: University of Alberta Executive Summary Spring 2013. Hanover, MD: American College Health Association; 2013. [cited May 10, 2020]. 18 p.

7. American College Health Association. American College Health Association-National College Health Assessment II: University of Alberta Executive Summary Spring 2016. Hanover, MD: American College Health Association; 2016. [cited May 10, 2020]. 18 p

8. American College Health Association. American College Health Association-National College Health Assessment II: University of Alberta Executive Summary Spring 2019. Silver Spring, MD: American College Health Association; 2019. [cited May 10, 2020]. 18 p.

9. Statistics Canada [Internet]. Ottawa: Statistics Canada; c2020. Cannabis legalization: what has changed? 2020 Feb 19 [updated 2020 Feb 20; cited 2020 May 27]; [about 2 screens]. Available from: https://www150.statcan.gc.ca/n1/pub/11-627-m/11-627-m2020014-eng.htm

10. Statistics Canada [Internet]. Ottawa: The Daily; c2020. National cannabis survey, first quarter 2019; 2019 May 2 [cited 2020 May 15].15 p. Available from: https://www150.statcan.gc.ca/n1/en/daily-quotidien/190502/dq190502a-eng.pdf?st=BuzJ5WrZ

11. Johnson JK, Doonan SM. Building evidence-based prevention mechanisms into cannabis legalization policy and regulations. Am J Public Health. 2019 Sep;109(9):11665-1166. Available from: https:// pubmed.ncbi.nlm.nih.gov/31390262/?from_single_result=Building+evidence-based+prevention+mechanisms+into+cannabis+legalization+policy+and+regulations.\&expanded_search_query=Building+evidence-based+prevention+mechanisms+into+cannabis+legalization+policy+and+regulations.

12. Tashkin DP, Roth MD. Pulmonary effects of inhaled cannabis smoke. Am J Drug Alcohol Abuse. 2019;45:596-609. Available from: https://pubmed.ncbi.nlm.nih.gov/31298945/?from_single_re- 
sult=18.+Tashkin+DP\%2C+Roth+MD.+Pulmonary+effects+of+inhaled+cannabis+smoke.+Am+J+Drug+Alcohol+Abuse.+2019\%3B45\%3A596-609\&expanded_search_query=18.+Tashkin+DP\%2C+Roth+MD.+Pulmonary+effects+of+inhaled+cannabis+smoke.+Am+J+Drug+Alcohol+Abuse.+2019\%3B45\%3A596-609

13. Caulley L, Caplan B, Ross E. Medical marijuana for chronic pain. N Engl J Med. 2018 Oct 18;379(16):1575-1577. Available from: https://www.nejm.org/doi/10.1056/NEJMclde1808149

14. Mashoon Y, Safar KA, Gruber SA. Cannabis use and consequences. Pediatr Clin N Am. 2019;66:10751086. Available from: https://pubmed.ncbi.nlm.nih.gov/31679598/?from_single_result=Mashoon+Y\%2C+Safar+KA\%2C+Gruber+SA.+Cannabis+use+and+consequences\&expanded_search_que$\mathrm{ry}=$ Mashoon $+\mathrm{Y} \% 2 \mathrm{C}+$ Safar $+\mathrm{KA} \% 2 \mathrm{C}+\mathrm{Gruber}+\mathrm{SA} .+$ Cannabis+use+and+consequences

15. Hauser W, Fitzcharles M, Radbruch L, Petzke F. Cannabinoids in pain management and palliative medicine. Dtsch Arztebl Intl. 2017 Sep;114(38):627-34. Available from: https://pubmed.ncbi.nlm.nih. gov/29017688/

16. Volkow ND, Baler RD, Compton WM, Weiss SRB. Adverse health effects of marijuana use. The $\mathrm{N}$ Engl J Med._2014 Jun 5;370:2219-27. Available from: https://pubmed.ncbi.nlm.nih.gov/24897085/

17. Hamilton AD, Jang JB, Patrick ME, Schulenber JE, Keyes KM. Age, period and cohort effects in frequent cannabis use among US students: 1991-2018. Addiction. 2019 Oct;114(10):1763-1772.

18. Cohen K, Weizman A, Weinstein A. Positive and negative effects of cannabis and cannabinoids on health. Clinical Pharmacology Therapeutics. 2019 May;105(5):1139-1147. Available from: https:// pubmed.ncbi.nlm.nih.gov/30703255/?from_term=Positive+and+negative+effects+of+cannabis+and+cannabinoids+on+health.\&from_pos=1

19. Murray JB. Marijuana's effects on human cognitive functions, psychomotor functions, and personality. J Gen Psychol. 1986 Jan;113(1):23-55. Available from: https://www.tandfonline.com/doi/abs/10.1080/ 00221309.1986.9710540 DOI: https://doi.org/10.1080/00221309.1986.9710540

20. Gobbi G, Atkin T, Zytynski T, Wang S, Askari S, Boruff J, Ware M, Marmorstein N, Cipriani A, Dendukuri $\mathrm{N}$, Mayo N. Association of cannabis use in adolescence and risk of depression, anxiety, suicidality in young adulthood: a systematic review and meta-analysis. JAMA Psychiatry. 2019; 76(4): 426-434. Available from: https://pubmed.ncbi.nlm.nih.gov/30758486/

21. Layden JE, Ghinai I, Pray I, Kimball A, Layer M, Tenforde MW, et al. Pulmonary illness related to e-cigarette use in Illinois and Wisconsin - final report. N Engl J Med. 2020 Mar 5;382(10):903-916. Available from: https://www.nejm.org/doi/pdf/10.1056/NEJMoa1911614?articleTools=true

22. Biehl JR, Burnham EL. Cannabis smoking in 2015: a concern for lung health?. Chest. 2015 Sep;148(2):596-606. Available from: https://pubmed.ncbi.nlm.nih.gov/25996274/ DOI: https://doi. org/10.1378/chest.15-0447

23. Graves BM, Johnson TJ, Nishida RT, Dias RP, Savareear B, Harynuk JJ, et al. Comprehensive characterization of mainstream marijuana and tobacco smoke. Sci Rep. 2020;10:7160. DOI: https://doi. org/10.1038/s41598-020-63120-6

24. Kelsall D. Cannabis legislation fails to protect Canada's youth. CMAJ. 2017 May;189. (21):E737-E738. Available from: http://www.cmaj.ca/content/189/21/E737.full DOI: https://doi.org/10.1503/ cmaj. 170555

25. Hammond CJ, Chaney A, Hendrickson B, Sharma P. Cannabis use among U.S. adolescents in the era of marijuana legalization: a review of changing use patterns, comorbidity, and health correlates. Int Rev Psychiatry. 2020 May;32(3):221-234. DOI: https://doi.org/10.1080/09540261.2020.1713056

26. Mader J, Smith JM, Afzal AR, Szeto ACH, Winters KC. Correlates of lifetime cannabis use and canna- 
bis use severity in a Canadian university sample. Addict Behav. 2019 Nov;98:106015. DOI: https://doi. org/10.1016/j.addbeh.2019.06.004

27. Statistics Canada [Internet]. Ottawa: Statistics Canada; c2020. Cannabis Stats Hub; 2019 [modified 2019 Oct 14; cited 2019 Oct 14]. Available from: https://www150.statcan.gc.ca/n1/pub/13-610-x/cannabis-eng.htm

28. Zuckermann AME, Battista K, de Groh M, et al. Prelegislation patterns and trends of cannabis use among Canadian youth: results from the COMPASS prospective cohort study. BMJ Open [Internet]. 2019 Jan [cited 2019 Aug 15];9:e026515. DOI: http://dx.doi. org/10.1136/bmjopen-2018- 026515

29. Yeung MEM, Weaver CG, Janz K, Haines-Saah R, Lang E. Clearing the air: a study of cannabis-related presentations to urban Alberta emergency departments following legalization. CJEM. 2020 Jun;1-8. DOI: https://doi.org/10.1017/cem.2020.384

30. Vogel L. What really happened after Colorado legalized marijuana? CMAJ. 2018 Oct 15;190(41):E12378. Available from: https://www.cmaj.ca/content/cmaj/190/41/E1237.full.pdf DOI: https://doi. org/10.1503/cmaj.109-5665

31. Russell C, Rueda S, Room R, Tyndall M, Fischer B. Routes of administration for cannabis use - basic prevalence and related health outcomes: a scoping review and synthesis. Int J Drug Policy. 2018 Feb;52:87-96. Available from: https://pubmed.ncbi.nlm.nih.gov/29277082/ DOI: https://doi. org/10.1016/j.drugpo.2017.11.008

32. Action on smoking and health [Internet]. Edmonton: ASH; c2020. Alberta policy resource hub: progress board municipalities; 2020 [cited 2020 May 29]; [about 7 screens]. Available from: https://ashpolicyhub.ca/alberta-hub/\#1578789821386-406304ef-d8c4

33. Government of Alberta [Internet]. Edmonton: Government of Alberta; c2020. Alberta cannabis framework and legislation: our framework and legislation set the stage for the legal and responsible use of cannabis by Albertans; 2020 [cited 2020 May 20]; [about 17 screens]. Available from: https://www. alberta.ca/cannabis-framework.aspx\#p6241s9

34. Davis AA. Maclean's [Internet]. Toronto: Maclean's; c2020. Canadian universities tackle legal cannabis with wildly different policies; 2018 Oct [cited 2020 Jun 20]; [about 22 screens]. Available from: https://www.macleans.ca/education/university-rankings/canadian-universities-tackle-legal-cannabis-with-wildly-different-policies/

35. Fallin A, Roditis M, Glantz SA. Association of campus tobacco policies with secondhand smoke exposure, intention to smoke on campus, and attitudes about outdoor smoking restrictions. Am J Public Health. 2015 Jun;105(6):1098-1100. Available from: https://pubmed.ncbi.nlm.nih.gov/25521901/

36. Lee JG, Ranney LM, Goldstein AO. Cigarette butts near building entrances: what is the impact of smoke-free college campus policies? Tob Control. 2013 Mar;22(2):107-112. Available from: https:// pubmed.ncbi.nlm.nih.gov/22135167/

37. Tan WC, Sin DD. What are the long-term effects of smoked marijuana on lung health? CMAJ. 2018 Oct 22;190(42):E1243-4. Available from: https://www.cmaj.ca/content/190/42/E1243

38. Stanbrook MB. Electronic cigarettes and youth: a gateway that must be shut. CMAJ. 2016;188(11):785. Available from: https://www.cmaj.ca/content/188/11/785

39. Government of Canada [Internet]. Ottawa: Government of Canada; c2020. Detailed tables for the Canadian Student Tobacco, Alcohol and Drugs Survey 2016-17; 2018 Jun 12 [cited 2020 Apr 9]; [about 53 screens]. Available from: https://www.canada.ca/en/health-canada/services/canadian-student-tobacco-alcohol-drugs-survey/2016-2017-supplementary-tables.html\#t5

40. Canadian Cancer Society [Internet]. Toronto: Canadian Cancer Society; c2020. University and college 100\% smoke-free campuses in Canada: national status report; 2018 Sep 14 [cited 2020 Apr 30]. 7 
p. Available from: https://www.cancer.ca/ /media/cancer.ca/CW/for\%20media/Media\%20releases/2018/University-college-100-percent-smoke-free-campus-national-report-2018-09-14.pdf?la=en

41. Daily News [Internet]. Hamilton: McMaster University; c2020. Tobacco and smoke free campus; 2017 [cited May 26, 2020]; [about 3 screens]. Available from: https://dailynews.mcmaster.ca/smoke-freecampus/

42. Brown S. Emergency physicians and public health experts call for tight regulations on cannabis edibles and concentrates. CMAJ. 2019 Jan 28;191(4):E111-E112. Available from: https://www.cmaj.ca/content/cmaj/191/4/E111.full.pdf DOI: https://doi.org/10.1503/cmaj.109-5703

43. Caputi TL. Medical marijuana industry and use of "research as marketing". Am J Public Health. 2020 Feb;110(2):174-175. Available from: https://pubmed.ncbi.nlm.nih.gov/31913671/?from_term=Medical+marijuana+industry+and+use+of+\%E2\%80\%9Cresearch+as+marketing $\% E 2 \% 80 \% 9 D .+\&$ from_pos $=2$

44. Watson TM, Valleriani J, Hyshka E, Rueda S. Cannabis legalization in the provinces and territories: missing opportunities to effectively educate youth?. Can J Public Health. 2019 Aug;110:472-475. Available from: https://pubmed.ncbi.nlm.nih.gov/31087281/?from_single_result=Cannabis+legalization+in+the+provinces+and+territories\%3A+missing+opportunities+to+effectively+educate+youth\%3F\&expanded_search_query=Cannabis+legalization+in+the+provinces+and+territories\%3A+missing+opportunities+to+effectively+educate+youth\%3F DOI: https://doi.org/10.17269/ s41997-019-00209-0

45. Lazard AJ, Horrell L, Pikowski J, Cornacchione Ross J, Noar SM, Sutfin EL. Message and delivery preferences for onlince tobacco education among adolescents and young adults. J Health Commun. 2018;23(8):735-742. DOI: https://doi.org/10.1080/10810730.2018.1523259

46. Richardson AK, Green M, Xiao H, Sokol N, Vallone D. Evidence for Truth: the young adult response to a youth-focused anti-smoking media campaign. Am J Prev Med. 2010;39(6):500-506.

47. Caulkins JP, Kilborn ML. Lower-risk cannabis use guidelines: will users listen? Am J Public Health. 2020 Jan;110(1):71-72. Available from: https://pubmed.ncbi.nlm.nih.gov/31800288/?from_single_result=Lower-risk+cannabis+use+guidelines\%3A+will+users+listen\%3F\&expanded_search_query=Lower-risk+cannabis+use+guidelines\%3A+will+users+listen $\% 3 \mathrm{~F}$ 